\title{
The Features of Mechanical Engineering English and Its English-Chinese Translation Principles
}

\author{
Chen $\mathrm{Chao}^{1, \mathrm{a}}$, Fang $\mathrm{Li}^{2, \mathrm{~b}}$ \\ ${ }^{1,2} 579$ Qianwangang Road Economic \& Technical Development Zone, Qingdao, Shandong \\ Province, P.R.China \\ achenchao7997@yahoo.com.cn, ${ }^{b}$ karenfang@sohu.com
}

Keywords: MEE translation, features, translation principles

Abstract: As a branch of English for Special Purposes, Mechanical Engineering English has its own features and rules. This article mainly discusses the basic features of MEE and tries to put forward some translation principles that are used in the mechanical engineering field.

\section{Introduction}

Along with the rapid development of the manufacturing industry, Mechanical Engineering English has been playing a more and more important role in the international cooperation and technical exchanges. As a medium, the translation of mechanical engineering writings, which play an important role in disseminating mechanical engineering technology internationally, challenges mechanical technicians. Consequently, it is of great significance to study the translation of Mechanical Engineering English systematically.

Mechanical Engineering English (MEE), a branch of English for Science and Technology and also a variety of English for Special Purposes, has its own features, rules and principals which differ from the common characteristics of general English. This thesis will deal with the language features of MEE from the perspective of vocabulary, grammar, style and discourse and propose some translation principles and techniques on MEE.

\section{Features of Mechanical Engineering English}

Different from the purposes of literature works which aim to provide texts for the readers to enjoy the artistic or aesthetic pleasure, mechanical engineering writing serves to spread knowledge and technologies in social science and natural science. Accordingly, mechanical engineering writing is usually logical, accurate and plain. Also, mechanical engineering writings are usually formal in style, standard in language, strict in logic, and objective in statement.

\section{Lexical features}

\section{Continual appearance of professional or technical vocabulary}

MEE possesses a lot of professional or technical words and there appear more and more new professional words with the rapid development of engineering industry. These words are pure in meaning, narrow in application and usually limited to a specific condition, e.g. “tribology (摩擦 学)”, “nano (纳米)”, “nanoprocessor (毫微秒处理机)”, “mechanotron (机械电子传感器)” etc.

\section{Wide use of semi-technical words}

Semi-technical words refer to those used both in general English and in MEE. These words with multiple meanings in MEE are in a great number. They are context-dependent words which occur with high frequency across fields. For example, as a noun, “work” means “工作”, but it means work piece (工件) in the field of smith craft,and sometimes means “part” (构件) and “constitution” (结构) in mechanical engineering. For more examples, please see the following table.

\begin{tabular}{|l|l|l|}
\hline words & General meaning & Meaning in MEE \\
\hline die & 死亡,灭亡 & 冲模,冲垫 \\
\hline exhaust & 耗尽,用尽 & 排气,排气装置 \\
\hline nose & 鼻子 & 轴端 \\
\hline
\end{tabular}




\begin{tabular}{|l|l|l|}
\hline pig & 猪 & 生铁 \\
\hline sound & 声音 & 探针,探测 \\
\hline stamp & 邮票 & 压印,压模 \\
\hline
\end{tabular}

\section{Grammatical features}

\section{Wide use of passive voice}

Usually writers are not encouraged to use passive voice, because of passive voice may cause monotonousness and awkwardness. However, scientists and engineers use the passive much more frequently than most other writers. It is because that as an objective information tool, mechanical engineering writings and readers are much more interested in objective rules and description of general process, much more concerned on action or facts than performers. Besides, the usage of passive voice allows more room to adjust sentence structure and adopt appropriate rhetorical devices, which will better enlarge information of the sentence and highlight relevant concepts, propositions and conclusions. For example:

(1) Springs are used as cushions to absorb shock.

In this sentence, passive voice is used to stress the importance of the subject.

(2) When a force is applied to a material, it produces a stress in the material.

Here, it is unnecessary to point out who is the performer.

(3) In most machine members, the deformation must be kept low.

In this sentence, it is hard to say who is the performer, thus, passive voice is used.

\section{Predominance of long sentences}

In order to illustrate the internal characteristics of the subjects and the mutual relations among different subjects clearly, it is necessary in MEE to use long and complex sentences due to the fact that long sentences can logically arrange the complicated information through various conjunctions to precisely expound theories, arguments and processes without the emergence of misunderstandings. Therefore, sentences in MEE may have not only one qualifier, modified speech or additional element, which produces the features of using long and complex sentences widely in MEE. Besides, it will simplify the long sentences in someway by employing infinitive phrases, gerund phrases and participle phrases.

In this way the distinction between heavy current electrical engineering and light current electrical engineering can be said to have disappeared,but we still have the conceptual difference in that in power engineering the primary concern is to transport energy between distant points in space; while with communication systems the primary objective is to convey,extract and process information,in which process considerable amounts of power may be consumed.

在这一方面,强电工程和弱电工程之间的区别可以说已经消失了; 但是我们仍旧认为它们 在概念上有所不同,因为电力工程的主要任务是在空间相距较远的各地之间输送能量,而通讯 系统的主要目的则是传递、提取和处理信息,尽管在这个过程中或许消耗相当大的电力。

\section{Translation principles of Mechanical Engineering English}

\section{Give priority to literal translation}

In MEE, there are little cultural difference and emotional meaning which only exist literature works. Thus, literal translation is in the first place when translating MEE writings. Besides, now that the feature of English is hypotaxis while that of Chinese is parataxis, it is necessary to first analyze the structures of English sentences before translation to get clear about the logic-semantic relation, find out the semantic stress and clarify the major part. In line with the Chinese writing habits, explicit semantic relations are changed into implicit ones so as to accomplish the conversion from hypotaxis to parataxis.

\section{Accurately understand the terms}

The abundant and complicated terms of MEE makes it incorrect to translate in accordance with the common meaning. Consequently, consulting professional dictionaries is required for accuracy.

The beam shall be arranged that the discharge of the content of the wagons is not impeded to any appreciable extent. 
横梁的设计要保证翻车卸货时不会被可预知的宽度所阻挡。

On seeing the translation, technicians will feel confused for it seems smooth but actually does not make any sense in meaning. With the assistance of the professional dictionary, it is easily found that "not impeded to any appreciable extent" in the sentence means small quantity of stores which should be translated as 横梁的设计要保证翻车卸货时存料量小。

\section{Acquaint with the actual operation instead of taking words literally}

Understanding the meanings of terms does not mean the accurate translation of the original text. It is required to acquaint the operating principles to get a better translation. For example, in a text about locomotive, there are such two sentences as, "If locomotives are required to run over the tippler, ...", "Where a locomotive is required to pass over or stand on the tippler, the tippler should be able to bear the load of the locomotive." If the translator does not know the structure and the operation of a locomotive, the translation would be like this: “如果要安装车头” and “当翻车机上 需要安装车头或停靠车头时,翻车机要能承受住车头的压力。” However, in the actual operation, tippler is a reversible equipment with a hollow $\mathrm{C}$ shape, in which the wagon is overturned. The locomotive refers to the one of the overturned wagon, and has nothing to do with the tippler. Thus, the right translation should be like this: “车若要通过翻车机平台...” and “当机车车头通过或停 靠在翻车机范围内时,翻车机必须能承受车头的压力”。

\section{Catch the main idea and translate flexibly}

The translation of the long sentence is perhaps the most difficult of all in the process of translation. The prerequisites for the correct handling of long sentences in translation lie in the translator's comprehension of the original text and his capability for adequate representation of the thought of the author in the target language. To achieve a smooth and faithful translation, translators should begin with a careful analysis of long sentences in line with the context so as to understand clearly: what the author is driving at; what logic sequence there is in the original; what grammatical relations there are among the many modifiers in the long sentences to be translated. For example:

Adequate compensating measures shall be taken in top and side bolster to cope with manufacturing imperfection within the permissible limits in the top coping and side stanchions of the wagons.

Translation 1: 顶垫及侧垫应有足够的补偿测量, 以便在顶盖和侧面支撑允许的范围内应付 施工时的不足。

Translation 2: 因制造时的缺陷,车皮顶盖和侧支撑有一定允许范围内的误差,这就要靠顶垫 和侧垫足够的补偿措施来弥补。

In translation 1, the translator's not figuring out what the attribute "within the permissible limits" modifies results in the unclear translation.

In translation 2, the translator identifies what the attribute modifies is "manufacturing imperfection", not "top and side bolster", adjusts the word order and makes the translation smoother and more easily understood.

Transform passive sentences into active ones in line with the Chinese structure

The wide use of the passive is considered to be one of the outstanding features of the English language, especially in its scientific works. This helps to focus the readers' attention on the thing, phenomenon or process described in MEE texts. Compared with English, Chinese has less passive structures. Therefore, in translation, we should try to convert the passive into various "active" patterns instead of sticking to the English patterns. For example, if the sentence "The wagon should be so designed that...” is translated into “车皮应该这样设计, 以确保...”, readers will feel uncomfortable although the translation fits into the meaning of the original text well. The right way is to change the English passive into Chinese active. It would be idiomatic and smooth if it is translated into “车皮的设计要保证...”.

\section{Conclusion}

Based on the analysis of the features of MEE and relevant translation principles, we can 
conclude that, to produce good translations, it is of great importance for translators to combine professional knowledge and the practical application, analyze the grammar and logical relation of the sentences and accurately understand the original texts in all round way. Furthermore, translators must have a sound knowledge of both English and Chinese and be ready to accumulate the accepted translations for the latest technical terms.

\section{References}

[1] Shi Ping: English in Mechanical Engineering (Harbin Institute of Technology Press, Harbin, 2010).

[2] Liao Fumei: The language features of Mechanical Engineering English and its Translation Strategy. Journal of Changsha University Vol. 24(2010)

[3] Qin Yan: The Discussion on the Translation Methods and Skills of Mechanical Engineering English. Ceramic Research \& Vocational Education Vol. 3 (2005)

[4] Wu Zhifang and Lv Fengzhen: The Lexical Features and Translation of Mechanical Engineering English. China Water Transport Vol. 6(2008)

[5] Zou Yu: Linguistic Features of Petroleum English and Its Translation. Chinese Science \& Technology Translators Journal Vol.20 (2007) 